\title{
Studi Karakteristik Campuran AC-Base Menggunakan Batu Gunung Pura Lau Kecamatan Tikala
}

\author{
Dede Novit Senolinggi ${ }^{\star 1}$, Alpius ${ }^{\star 2}$, Charles Kamba ${ }^{\star 3}$ \\ *1 `Mahasiswa Program Studi Teknik Sipil, Universitas Kristen Indonesia Paulus, Makassar, Indonesia \\ Dedenovit21@gmail.com \\ *2 Dosen Program Studi Teknik Sipil, Universitas Kristen Indonesia Paulus, Makassar, Indonesia \\ alpiusnini@gmail.com \\ *3 Dosen Program Studi Teknik Sipil, Universitas Kristen Indonesia Paulus, Makassar, Indonesia \\ Kamba.charles@gmail.com
}

\begin{abstract}
ABSTRAK
Penelitian ini bertujuan untuk mendapatkan karakteristik pada setiap agregat batu Gunung Pura lau kecamatan tikala. Metodologi penelitian ini yaitu dengan menguji setiap karakter dari sampel yang akan di uji baik itu jenis agregat kasar, agregat halus, filler, dan aspal. Setelah menguji setiap karakter dari setiap sampel, kita akan merancang komposisi campuran untuk pembuatan benda uji jenis Laston Base (AC-BASE) dan didapatkan beberapa varian. Seteelah di dapatkan komposisinya, maka benda uji akan segera dibuat. Setelah benda uji dibuat, saatnya untuk diuji dengan alat pengujian Marshall untuk mendapatkan Indeks Perendaman / Stabilitas Marshall Sisa (SMS) dengan menggunakan Kadar aspal optimum. Adapun hasil dari Kadar aspal optimum yaitu 5,5\%, MQ 906,88 Kg/mm dan indeks perendaman (IP) 96,06\% yang menunujukkan bahwa campuran Laston Base yang menggunakan batu Gunung Pura Lau Kecamatan Tikala ini memenuhi persyaratan yaitu 90\% dan memenuhi spesifikasi Bina Marga. Sehingga dapat dijadikan rekomendasi kepada pemerintah wilayah serta warga setempat.
\end{abstract}

Kata kunci : Karakteristik, Campuran Laston Base, AC-BASE.

\begin{abstract}
This study is to get character each of Laston base mixture using the Mount Pura Lau stone, Tikala District. The methodology in this study is to test each character of the sample to be tested for its, whether it is coarse aggregate, fine aggregate, filler, and asphalt. After testing each character, we will design the composition of the mixture for the manufacture of rough Laston Base (AC-BASE) specimens and obtain several variants of asphalt content, namely $4.5 \%$, $5 \%, 5.55 \%, 6 \%$, and $6.5 \%$. After getting the composition, the test object will be made immediately. After the object has been made, it is time to test with Marshall test tool to obtain the residual Marshall Immersion / Stability Index (SMS) or the durability of the mixture using the optimum bitumen content. The results of the optimum asphalt content were $5.5 \%$, MQ $906.88 \mathrm{Kg} / \mathrm{mm}$ and immersion index (IP) 96.06\% which showed that met the requirements, namely $90 \%$ and meets the specifications of Bina Marga. So that it can be used as a recommendation to the regional government and local residents.
\end{abstract}

Keywords: Characteristics, Laston Base Mix, AC-BASE

\section{PENDAHULUAN}

Batu gunung merupakan batuan yang mengandung Kapur serta dapat kita ditemui di wilayah Pegunungan. Batu gunung saat ini sering digunakan untuk Kebutuhan pembangunan di masing- masing [1] daerah di Toraja Utara terutama di Kecamatan Tikala yang menjadi perkembangan kebutuhan material buat pembangunan terlebih di sektor prasarana jalur terus menjadi bertambah. Pengembangan jalur di Kabupaten Toraja Utara kecamatan Tikala biasanya memakai batu dari luar wilayah. Kebutuhan bayaran untuk membawa batu dari luar wilayah butuh bayaran besar. Menggunakan sumber energi alam yang terdapat di daerah. sekitar menjadi salah satu alternatif untuk meminimalisir kebutuhan biaya dalam mendatangkan bahan. Tersedianya agregat batu gunung di Tikala selaku bagian dari kekayaan alam di Kecamatan Tikala, menjadi salah satu opsi yang diharapkan bisa jadi opsi dijadikannya bahan agregat. Sehingga pembangunan di wilayah itu dapat berjalan dengan maksimal, maka dari itu pemakaian bahan disekitar wilayah di utamakan, sebab adanya sumberdaya. Secara umum, perkerasan terbagi menjadi lapis permukaan (AC$W C)$, lapisan antara $(A C-B C)$, serta lapisan pondasi 
Paulus Civil Engineering Journal

Jurnal Teknik Sipil UKI-Paulus Makassar https://doi.org/10.52722/pcej.v3i2.3215

(LASTON BASE) Tipe perkerasan yang digunakan ialah lapis aspal Beton (LASTON). yang diproduksi dari hasil pencampuran agregat agresif, agregat halus, filler, serta aspal dengan temperatur tertentu setelah itu dilepas dan di padatkan pada temperature yang sudah ditentukan setiap Kadar aspal sebagai bahan pembentuk wajib dihitung sampai kombinasi yang didapat terpenuhi. kriteria kerja selaku bahan, ialah bernilai tertentu, baik itu dari durabilitas, awet, dan murah. [2]. Pemakaian bahan di Gunung Pura Lau tidak diteliti secara spesifik dalam kombinasi AC-BASE, sebabnya penelitian ini hendak diketahui kualitas bahannya, dimana ada pengujian karakteristik bahan, perancangan bahan kombinasi serta uji ciri kombinasi AC- BASE, untuk mengetahui bagus ataupun kurangnya mutu bahan tersebut bisa digunakan dan layak selaku bahan pengembangan fasilitas transportasi terkhusus dalam susunan lapisan AC- BASE.

Lapis aspal beton (LASTON) ialah suatu susunan jalur dan terdiri dari kombinasi aspal, batu, serta bahan pengisi( filler).

\section{METODE PENELITIAN}

Tempat mendapatkan bahan yang akan di teliti berada di Gunung Pura Lau Kecamatan Tikala Toraja Utara, diambil mengunakan tangan yang di kumpul dari beberapa pecahan batu dari beberapa titik dilokasi yang sama dan dimasukan kedalam karung. Jumlah material yang dibutuhkan dalam penelitian ini sekitar $20 \mathrm{~kg}$. Kecamatan Tikala ke Rantepao memiliki jarak $\pm 20 \mathrm{~km}$.

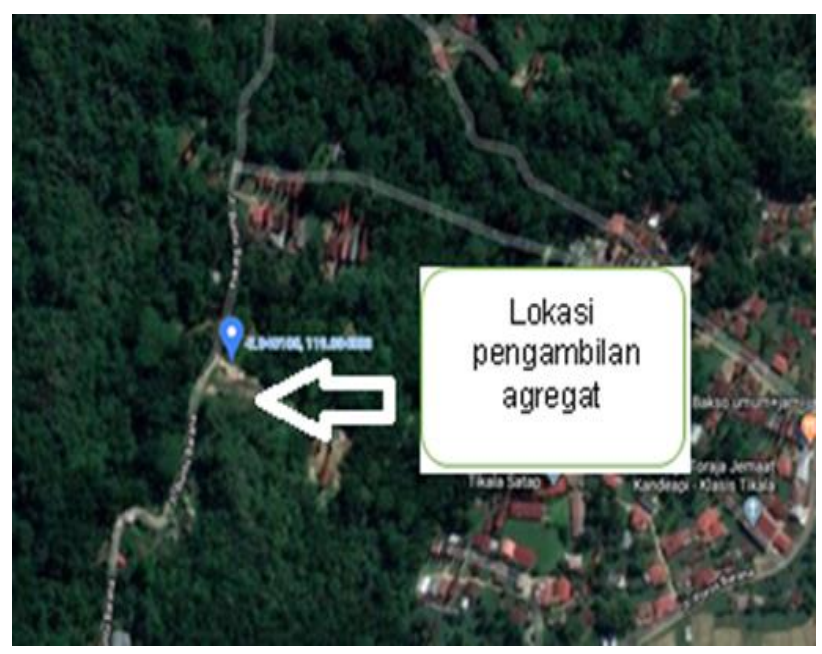

Gambar.1. Lokasi agregat

\section{Pemeriksaan Karakteristik Agregat}

Volume 3 No.2, Juni 2021

e-ISSN 2775-4529

p-ISSN 2775-8613

Pemeriksaan dimulai dengan Analisa Saringan yang bertujuan membuat suatu distribusi butir (gradasi) suatu agregat yang memakai saringan. Pemerikaan Berat Kategori Curah serta Penyerapan Air Agregat kasar dan halus untuk menetukan berat tipe serta penyerapan agregat kasar dan halus serta mengelompokkannya ke bagian berat jenisnya. Pengecekan Partikel Pipih serta Lonjong ialah untuk memastikan indeks pipih serta lonjong suatu batu dan bisa dijadikan kombinasi aspal lalu dinyatakan dalam persen. Pengecekan Kandungan tanah untuk mengenali tingkatan persentase kandungan lumpur pada suatu agregat. Tes agregat lulus ke Saringan No.200 untuk mengukur persenan jumlah batuan secara sampel lulus filler 200 agar bermanfaat untuk perencanaan dan menerapkan konstruksi jalan. Tes keausan yaitu mendapatkan nilai keausan keseluruhan menggunakan mesin Los Angeles pada bobot filler No.12 dengan berat asli Pengujian Kelekatan Agregat pada aspal untuk dapat kelekatan agregat pada aspal. [3]

\section{Karakteristik Campuran Beraspal}

Pengujian Penetrasi pada $25^{\circ} \mathrm{C}$ (SNI 2456 - 2011) (Data primer) adalah metode yang digunakan untuk memperoleh nilai kekerasan aspal dengan mengaplikasikan pengujian penetrasi mengenakan alat penetrometer. uji Titik Nyala (OC ) (SNI 24332011) (Data primer) Tujuannya yakni memahami temperatur aspal mulanya menghasilkan nyala serta dibakar karena panas. Pengujian Titik Lembek (OC ) (SNI 2434-2011) (Data primer) bertujuan untuk mengetahui temperatur aspal lembek memakai alat ring plus ball dan temperatur ini jadi acuan kapabilitas aspal agar temperatur yang berlangsung tidak lembek. Pengujian Berat Jenis (SNI 24412011) (Data primer) Tujuannya ialah memahami berat jenis aspal. Pengujian Daktilitas pada $25^{\circ} \mathrm{C}$ (SNI 2432-2011) (Data primer) ialah mengetahui kekenyalan aspal yang dinyatakan saat panjangnya uluran aspal yang diinginkan sesaat sebelum putus. Pengujian Berat Jenis yang Hilang (\%) (SNI 062441-1991) (Data primer) tujuannya untuk mengetahui kehilangan minyak pada aspal akibat pemanasan yang di ulangi serta termasuk mempunyai tujuan mengkalkulasi perubahan aspal yang kehilangan berat. Pengujian Penetrasi terhadap $25^{\circ} \mathrm{C}$ TFOT (SNI 03- 6835- 2002) (Data primer) bertujuan menentukan penurunan berat minyak dan aspal yaitu dengan pemanasan dari tebal tertentu, dan dinyatakan dalam persen 
Paulus Civil Engineering Journal

Jurnal Teknik Sipil UKI-Paulus Makassar https://doi.org/10.52722/pcej.v3i2.3215

\section{Menentukan rancangan Campuran AC- BASE}

Aspal memiliki 3 (tiga) bahan utama yaitu agregat, aspal,serta filler. Dan untuk memenuhi karakteristik campuran tersebut, maka rancangan campuran harus mengacu pada spesifikasi Umum Bina Marga 2018. Yang utama dalam rancangan campuran adalah Gradasi pada campuran tersebut, sehingga untuk mendapatkan karakteristik campuran yang baik maka gradasi yang digunakan yaitu gradasi ideal dengan mengambil nilai tengah daripada batasan gradasi itu (batas atas dan bawah gradasi/ rata-rata batas gradasi) yang dapat dilihat pada tabel 1:

Tabel 1. Komposisi Campuran AC-BASE

\begin{tabular}{ccc}
\hline \multirow{2}{*}{$\begin{array}{c}\text { Ukuran } \\
\text { Ayakan } \\
(\mathrm{mm})\end{array}$} & \multicolumn{2}{c}{$\begin{array}{c}\text { \% Berat Lolos terhadap total Agregat } \\
\text { dalam }\end{array}$} \\
\cline { 2 - 3 } & $\begin{array}{c}\text { Campuran Laston } B A S E \\
\text { Gradasi }\end{array}$ & $\begin{array}{c}\text { Rancangan Gradasi } \\
\text { Campuran }\end{array}$ \\
\hline $1 \frac{1}{2}$ & 100. & 100. \\
1 & $90-100$. & 95. \\
$3 / 4$ & $76-90$ & 83 \\
$1 / 2$ & $60-78$ & 69 \\
$3 / 8$ & $52-71$ & 61,5 \\
4 & $35-54$ & 44,5 \\
8 & $23-41$ & 32 \\
16 & $13-30$ & 21,5 \\
30 & $10-22$ & 16 \\
50 & $6-15$ & 10,5 \\
100 & $4-10$ & 7 \\
200 & $3-7$ & 5 \\
\hline
\end{tabular}

\section{Komposisi Campuran}

Setelah seluruh bahan yang dibutuhkan mencukupi spesifikasi, tahapan setelah itu adalah kuantitas contoh sampel dan persiapan bahan bersamaan komposisi campuran (Mix design) yang diperoleh. Perhitungan kadar aspal perkiraan mula-mula ACBASE [4]

$\begin{array}{ll}\text { Kadar aspal efektif min } & =0,6 \% \\ \text { Kadar aspal efektif mak } & =1,2 \% \\ \text { Lolos ayakan No. } 200 & =5 \% \\ \text { Kadar aspal rancangan mak } & =8,33 \% \\ \text { Kadar aspal rancangan min } & =4,17 \%\end{array}$

Dari kadar rancangan didapatkan nilai $4,17 \%$ sampai $8,33 \%$ kemudian dibulatkan menjadi 4,5\% sampai $8 \%$. Dengan Kenaikan $0,5 \%$, maka rancangan kadar aspal sedikitnya 4,5\%, 5\%, 5,5\%, $6 \%, 6,5 \%$. Seperti pada tabel 2 berikut

Tabel 2. Komposisi Campuran

\begin{tabular}{cccccc}
\hline Kadar & \multicolumn{5}{c}{ LASTON BASE } \\
aspal (\%) & $4.5 \%$ & $5 \%$ & $5.5 \%$ & $6 \%$ & $6.5 \%$ \\
\hline $\begin{array}{c}\text { Berat } \\
\text { agregat } \\
(\mathrm{gr})\end{array}$ & 1090 & 1085 & 1079 & 1074 & 1068 \\
$\begin{array}{c}\text { Berat } \\
\text { aspal (gr) }\end{array}$ & 54 & 60 & 66 & 72 & 78 \\
$\begin{array}{c}\text { Berat } \\
\text { campuran } \\
\text { (gr) }\end{array}$ & 1200 & 1200 & 1200 & 1200 & 1200 \\
& & & & & \\
\end{tabular}

\section{Pengujian Marshall Konvensional}

Tahapan pembuatan sampel ialah menimbang dan memanaskan agregat sesuai proporsi, menimbang dan memanaskan aspal, mengkombinasikan agregat serta aspal, mengaduk kombinasi AC- Base sampai homogen, memadatkan memakai mesin automatic compactor dengan 75 tumbukan pada kedua sisi permukaan barang uji, melakukan pengujian Marshall. [5] Sebelum dikerjakan pengujian benda uji, Benda Uji perlu bersih berasal dari kotoran organik, [6] serta bahan yang lainnya. Lalu tiap-tiap sampel diberi tanda untuk mengenal kuantitas sampel yang dinamakan, dan tinggi benda uji dengan pakai jangka ketelitian $0,1 \mathrm{~mm}$. Pengujian bertujuan memperoleh stabilitas dan lelehan. Analisa kepadatan dan lubang kecil campuran padat yang berbentuk dicoba metode timbang sampel. Setelah pembuatan benda uji telah selesai, sampel didiamkan \pm 24 jam, setelah itu dikalkulasi untuk mendapatkan berat pada saat dikeringkan. Setelah itu sampel direndam untuk mendapatkan berat dalam air serta berat SSD. Pengujian marsall dicoba pada perlengkapan marshal, setelah benda uji pertama direndam dengan suhu $60^{\circ} \mathrm{C}$. Dari pemeriksaan Marshall akan diperoleh angka ciri marshall seperti: stabilitas, flow, Marshall Quotient( $M Q$ ), Rongga Antara Mineral Agregat( VMA), Rongga dalam kombinasi( VIM) serta Rongga Terisi aspal( VFA). [7]

\section{Kadar Aspal Optimum}


Paulus Civil Engineering Journal

Jurnal Teknik Sipil UKI-Paulus Makassar https://doi.org/10.52722/pcej.v3i2.3215

Sampel yang sudah di uji marshall konvensionalnya, kemudian dikalkulasi untuk dapat Kadar Aspal Optimum. Data yang telah diambil lalu diinput dalam kolom data. lalu kombinasi AC- BASE di seleksi dan yang mempunyai nilai stabilitas terbanyak ialah pada aspal 5. 00\% yang didapatkan dari nilai paling tingi stabilitas, campuran yang dipadatkan dengan persentase aspal.

\section{Pengujian Marshall Immersion}

Marshall Immersion adalah uji sampel yang melihat durabilitas sampel untuk mendapatkan rasio stabilitas. Rasio berikut membandingkan stabilitas sampel di Marshall setelah direndam dengan temperatur $60^{\circ} \mathrm{C}$ dalam bak air selama 24 jam. [6]

\section{HASIL DAN PEMBAHASAN}

\section{Karakteristik Material}

\section{a. Agregat}

Hasil analisa saringan berwujud pembagian batuan serta spesifik yang mana pembagian butir batuan ada di tengah batas atas dan batas bawah, ini memperlihatkan batuan yang dipakai mencukupi standar. Dari uji tersebut, telah didapatkan dari Gambar 2. Hasil uji keausan agregat bersamaan memakai mesin Los Angeles didapatkan angka ketahanan batuan kasar pada keausan dari Slot 1 senilai $5,6 \%$, Slot 2 sebesar $5,78 \%$, Slot 3 adalah $8,36 \%$ dan Slot 4 sebesar 8,52\%. Dan semua hasil uji, tiap slot memenuhi standar Spesifikasi, yakni dengan nilai $10 \%$. Sehingga, disimpulkan bahwa agregat dari Gunung Pura Lau yang akan digunakan sebagai bahan susunan permukaan jalur mampu bertahan pada keausan akibat gesekan pada batuan atau agregat bersamaan dengan ban kendaraan. Hasil uji lolos saringan Nomor 200 didapat hasil 4,60 sehingga sesuai spesifikasi 2018 yakni maks. Setelah uji berat jenis dan penyerapan batuan kasar memakai dua sampel didapat angka Berat Jenis Bulk 2,68 persen, berat jenis SSD 2,72 $\%$, berat jenuh 2,78 persen dan Penyerapan Air adalah 1,26\%. Semua hasil pengujian memenuhi Spesifikasi Umum yakni untuk Berat Jenis Bulk, Berat Jenis SSD dan Berat Jenis Semu adalah sedikitnya 2,5\% dan Penyerapan Air maksimal 3\% atau serapannya kecil. [8] Setelah dilakukan uji Berat Jenis dengan Penyerapan Agregat Halus didapat nilai Berat Jenis Bulk 2,71\%, Berat Jenis SSD ialah 2,76 \%, Berat Jenis jenuh ialah 2,84 prosen dan serapan Air $1,73 \%$. Semua uji memenuhi Spesifikasi Umum untuk Berat Jenis adalah sedikitnya 2,5\%, Berat Jenis SSD adalah sedikitnya $2,5 \%$, Berat Jenis Semu adalah sedikitnya 2,5 prosen dan Penyerapan Air maksimal adalah 3\%. [8] Angka uji Kadar lumpur yang mana angka uji kandungan lumpur diperoleh nilai Sand Equivalent (SE) 96,06 \% dan kadar lumpur mengandung 3,94\%. Yang mana sudah cocok dengan spesifikasi Bina Marga yakni minimal 50\% untuk Equivalent Of Sand pengujian berat jenis filler diperoleh 3,05\%. Untuk filler yang dipakai di dalam penelitian ini adalah Semen Portland. Setelah uji Indeks pipih dan lonjong untuk butiran Kasar. Hasil uji indeks pipih dan lonjong butiran kasar didapatkan kriteria pipih yaitu 8,20\%, 5,70\%, 7,70\%, dan 7,60\%. Dan kriteria lonjong yakni 8,'20\%, 5,70\%, 7,10\% serta $9,20 \%$. kriteria tersebut sesuai spesifikasi yakni maksimal 10\% [8]

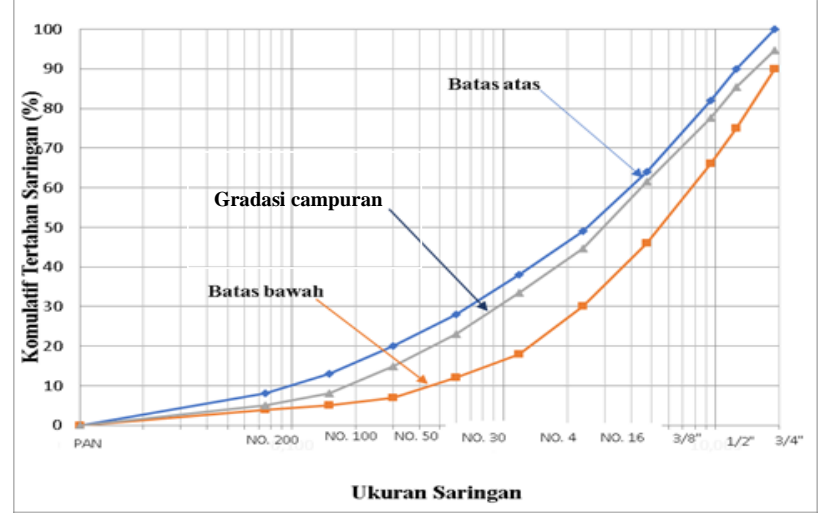

Gambar 2. Grafik analisa saringan agregat

Hasil uji keausan agregat bersamaan memakai mesin Los Angeles didapatkan angka ketahanan batuan kasar pada keausan dari Slot 1 senilai $5,6 \%$, Slot 2 sebesar 5,78\%, Slot 3 adalah 8,36\% dan Slot 4 sebesar $8,52 \%$. Dan semua hasil uji, tiap slot memenuhi standar Spesifikasi, yakni dengan nilai $10 \%$. Sehingga, disimpulkan bahwa agregat dari Gunung Pura Lau yang akan digunakan sebagai bahan susunan permukaan jalur mampu bertahan pada keausan akibat gesekan pada batuan atau agregat bersamaan dengan ban kendaraan. Hasil uji lolos saringan Nomor 200 didapat hasil 4,60 sehingga sesuai spesifikasi 2018 yakni maks. Setelah uji berat jenis dan penyerapan batuan kasar memakai dua sampel didapat angka Berat Jenis Bulk 2,68 persen, berat jenis SSD 2,72 \%, berat jenuh 2,78 persen dan Penyerapan Air adalah 1,26 $\%$. Semua hasil pengujian memenuhi Spesifikasi 
Paulus Civil Engineering Journal

Jurnal Teknik Sipil UKI-Paulus Makassar https://doi.org/10.52722/pcej.v3i2.3215

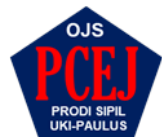

Volume 3 No.2, Juni 2021

e-ISSN 2775-4529

p-ISSN 2775-8613
Umum yakni untuk Berat Jenis Bulk, Berat Jenis SSD dan Berat Jenis Semu adalah sedikitnya 2,5\% dan Penyerapan Air maksimal 3\% atau serapannya kecil. [8] Setelah dilakukan uji Berat Jenis dengan Penyerapan Agregat Halus didapat nilai Berat Jenis Bulk 2,71 \%, Berat Jenis SSD ialah 2,76 \%, Berat Jenis jenuh ialah 2,84 prosen dan serapan Air 1,73 $\%$. Semua uji memenuhi Spesifikasi Umum untuk Berat Jenis adalah sedikitnya 2,5\%, Berat Jenis SSD adalah sedikitnya 2,5\%, Berat Jenis Semu adalah sedikitnya 2,5 prosen dan Penyerapan Air maksimal adalah 3\%. [8] Angka uji Kadar lumpur yang mana angka uji kandungan lumpur diperoleh nilai Sand Equivalent (SE) 96,06 \% dan kadar lumpur mengandung 3,94\%. Yang mana sudah cocok dengan spesifikasi Bina Marga yakni minimal $50 \%$ untuk Equivalent Of Sand pengujian berat jenis filler diperoleh $3,05 \%$. Untuk filler yang dipakai di dalam penelitian ini adalah Semen Portland. Setelah uji Indeks pipih dan lonjong untuk butiran Kasar. Hasil uji indeks pipih dan lonjong butiran kasar didapatkan kriteria pipih yaitu 8,20\%, 5,70\%, 7,70\%, dan $7,60 \%$. Dan kriteria lonjong yakni $8,20 \%$, $5,70 \%, 7,10 \%$ serta $9,20 \%$. kriteria tersebut sesuai spesifikasi yakni maksimal 10\% [8]

\section{b. Aspal}

Hasil penetrasi didapat nilai $66,7 \mathrm{~mm}$. Hasil tersebut sudah mencukupi Spesifikasi Umum yakni minimal $60 \%$ - maksimum $70 \%$ untuk nilai penetrasi aspal. [8] Hasil uji titik lembek aspal didapat nilai umumnya $50,2^{\circ} \mathrm{C}$. Hasil ini masuk didalam Spesifikasi yakni $\geq$ $48{ }^{\circ} \mathrm{C}$. Hasil uji Titik Nyala dan Bakar didapatkan kebanyakan 290. Hasil ini masuk didalam Spesifikasi yaitu $\geq 232{ }^{\circ} \mathrm{C}$. Setelah diuji kehilangan berat aspal didapatkan nilai biasanya 0,434. dan masuk didalam Spesifikasi $\leq 0,8 \%$. Untuk uji penetrasi TFOT didapat biasanya 56,5\%. Dan sesuai didalam syarat yang dicantumkan didalam Spesifikasi yaitu $\geq 54$ prosen sebelum kehilangan berat. Hasil uji daktilitas didapat nilai biasanya 150 . Hasil ini masuk didalam syarat yang ditentukan didalam Spesifikasi yaitu $\geq 100$. Setelah dilakukan uji Berat Jenis didapat biasanya 1,015. Yang mana masuk didalam persyaratan yaitu $\geq 1,0$

\section{Marshall Konvensional}

Beda uji dibentuk bersama persentase AC- BASE seperti 4,5\%, 5,0\%, 5,5\%, 6,0\%, 6,5\%. Hasil kalkulasi dapat dilihat di Tabel berikut.

Tabel 3. Spesific Gravity dan Efective Spesific Gravity

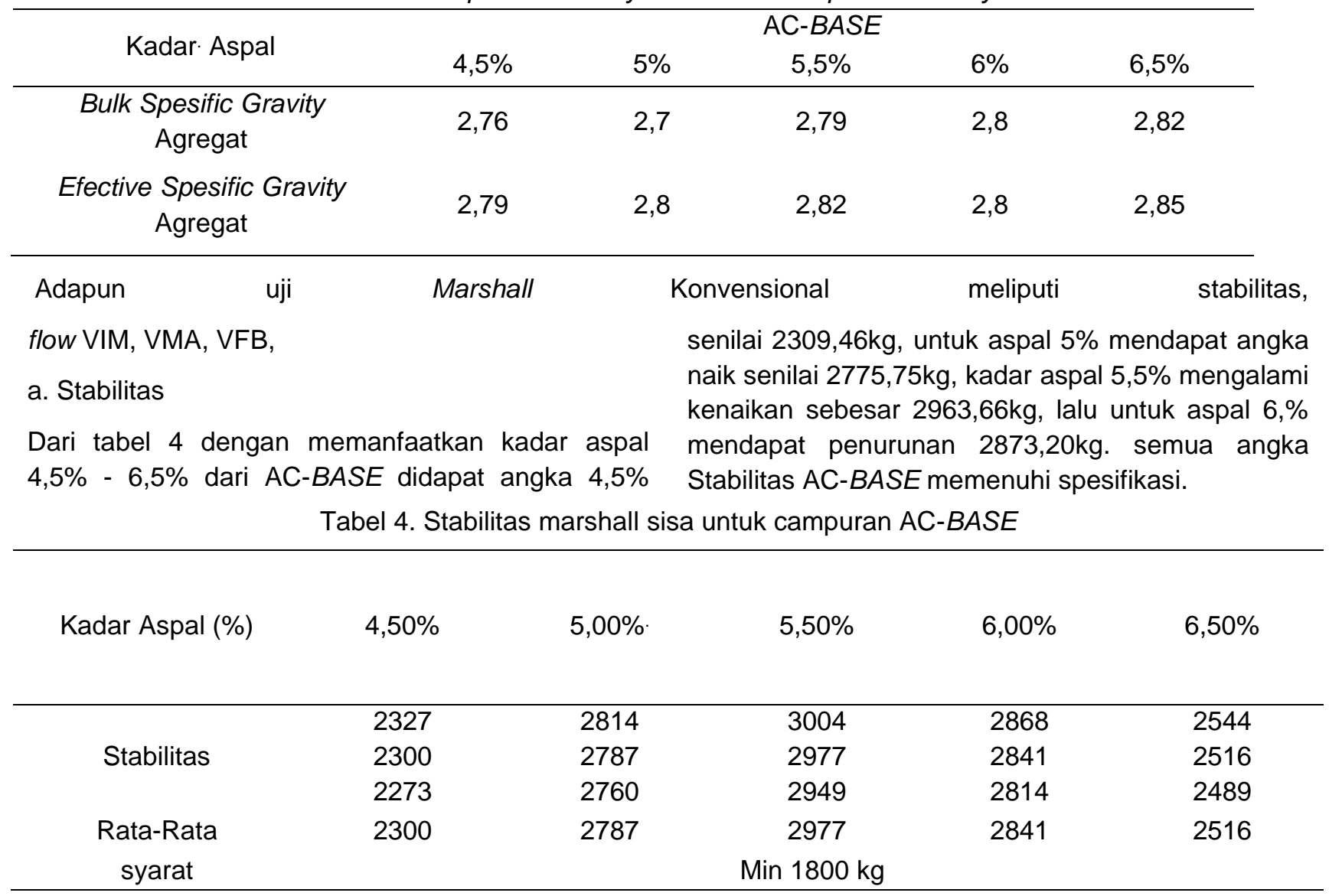


Paulus Civil Engineering Journal Jurnal Teknik Sipil UKI-Paulus Makassar https://doi.org/10.52722/pcej.v3i2.3215

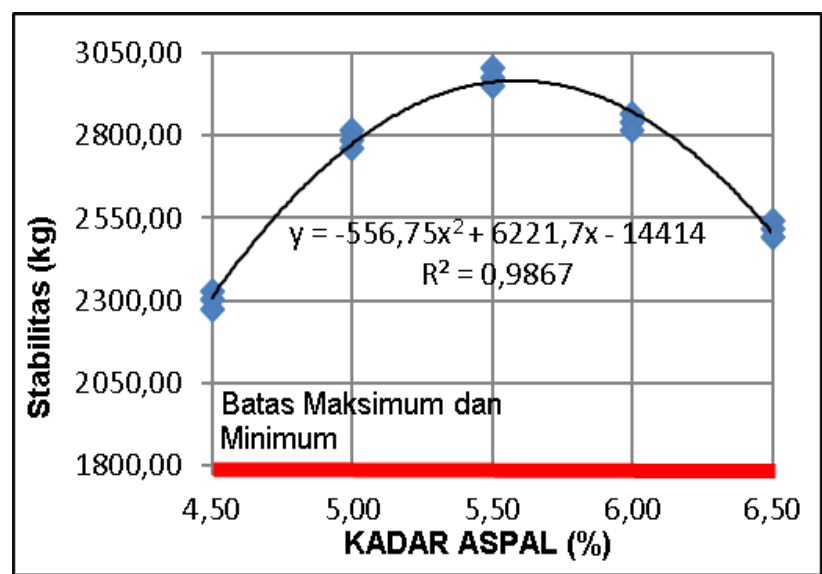

Gambar 3. Grafik hubungan laston dan stabilitas

Melihat grafik di atas dapat disimpulkan bahwa nilai tertinggi didapat dari campuran dengan kadar aspal $5.5 \%$ yakni $2963,66 \mathrm{~kg}$. dari grafik tersebut dapat di ketahui pemakaian aspal yang minim di AC-BASE bakal memberikan selimut aspal yang kurang tebal pada permukaan agregat sehingga menyebabkan kuncian antar agregat jadi lemah sehingga stabilitas menurun.

b. VIM

Dari tabel 5 dengan memakai kadar aspal 4,5\% $6,5 \%$ AC-BASE didapatkan kadar aspal 4,5\% sebesar 4,97\%. Dari kadar aspal 4,5\% - 6,5\% telah memenuhi persyaratan. Dari grafik tersebut, dapat diketahui makin besar kadar aspal yang digunakan maka pori didalam campuran dapat diisi aspal. Jika kadar aspal yang dipakai makin lama makin kecil maka pori pada campuran tidak terisi aspal, sehingga nilai VIM makin tinggi. [6] Dari Grafik diatas bisa diketahui bahwa menggunakan banyak

\begin{tabular}{cccccc}
\hline $\begin{array}{c}\text { Kadar } \\
\text { Aspal }\end{array}$ & $\begin{array}{c}4.50 \\
\%\end{array}$ & $\begin{array}{c}5.00 \\
\%\end{array}$ & $\begin{array}{c}5.50 \\
\%\end{array}$ & $\begin{array}{c}6.00 \\
\%\end{array}$ & $\begin{array}{c}6.50 \\
\%\end{array}$ \\
\hline Flow. & 4,10 & 4,00 & 3,90 & 4,40 & 4,70 \\
& 3.90 & 3,90 & 3,80 & 4,30 & 4,60 \\
& 4,00 & 3.90 & 3.80 & 4,20 & 4,50 \\
Rata- \\
rata \\
syarat
\end{tabular}

Tabel 5. Pengujian VIM Campuran AC-BASE
Volume 3 No.2, Juni 2021 e-ISSN 2775-4529 p-ISSN 2775-8613 kadar

aspal

\section{$4.50 \% \quad 5.00 \% \quad 5.50 \% \quad 6.00 \% \quad 6.50 \%$}

\begin{tabular}{lccccc}
\hline & 4.98 & 4.67 & 4.22 & 3.68 & 3.59 \\
& 4.96 & 4.65 & 4.20 & 3.98 & 3.57 \\
VIM. & 4.94 & 4.63 & 4.28 & 3,86 & 3.55 \\
& 4.96 & 4.65 & 4.24 & 3.91 & 3.57 \\
$\begin{array}{c}\text { Rata- } \\
\text { rata } \\
\text { syarat }\end{array}$ & & & $3-5(\%)$ & & \\
\hline
\end{tabular}

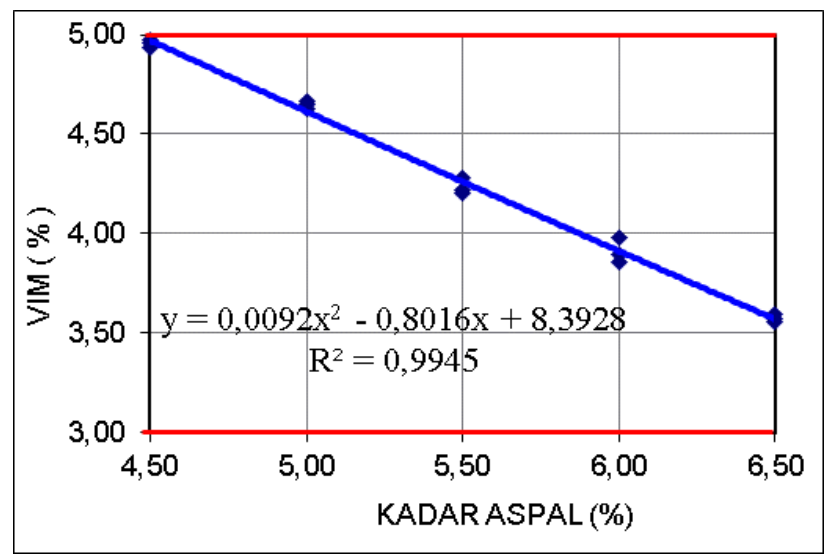

Gambar 4. Grafik hubungan kadar aspal dan VIM

c. Flow

Dari tabel 6 yang menggunakan persentase aspal $4,5 \%-6,5 \%$ pada AC-BASE didapatkan nilai sekitar $4,00 \mathrm{~mm}-4,60 \mathrm{~mm}$. Persentase aspal 4,5\% - 6,5\% untuk AC-BASE seluruhnya mencukupi Spesifikasi.

Tabel 6. Pengujian Flow campuran AC-BASE

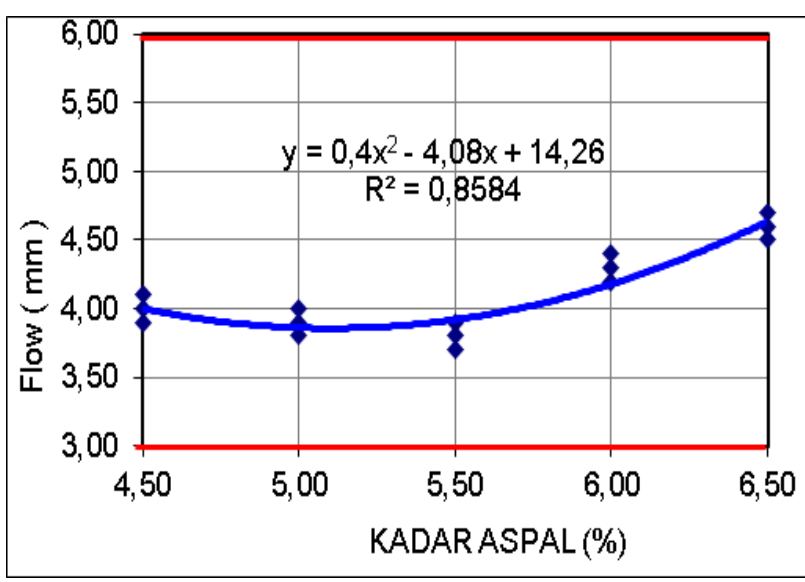

Gambar 5.Grafik hubungan kadar aspal dan flow

Berdasarkan grafik tersebut dapat di ketahui jika 
Paulus Civil Engineering Journal Jurnal Teknik Sipil UKI-Paulus Makassar https://doi.org/10.52722/pcej.v3i2.3215

pemakaian aspal kecil, maka ikatan antar agregatnya menyusut yang menyebabkan kelenturan besar.

d. VMA

Dari tabel 7 didapat angka VMA kadar aspal 4,5\% senilai $14.65 \%$, dan untuk aspal $5 \%$ mengalami

Kadar

Aspal

$\begin{array}{lllll}4.50 \% & 5.00 \% & 5.50 \% & 6.00 \% & 6.50 \%\end{array}$

\begin{tabular}{|c|c|c|c|c|c|}
\hline \multirow{3}{*}{ VFB } & 66.06 & 69.98 & 74.12 & 77.32 & 80.11 \\
\hline & 66.15 & 70.07 & 74.22 & 76.93 & 80.20 \\
\hline & 66.25 & 70.16 & 73.83 & 77.50 & 80.29 \\
\hline $\begin{array}{l}\text { Rata- } \\
\text { rata }\end{array}$ & 66.15 & 70.07 & 74.05 & 77.25 & 80.20 \\
\hline syarat & \multicolumn{5}{|c|}{ Min 65 (\%) } \\
\hline
\end{tabular}

Tabel 7. Pengujian VMA Campuran AC-BASE

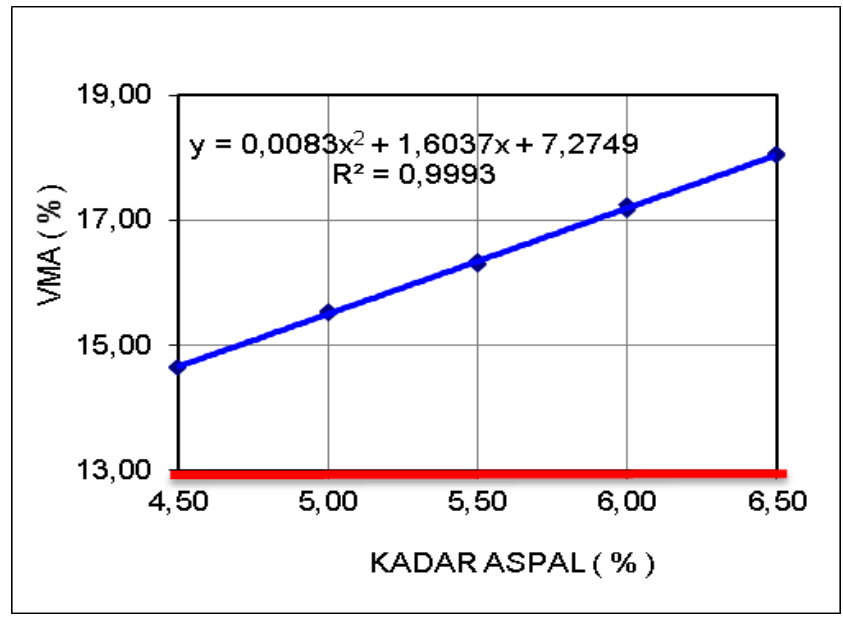

Gambar 6. Grafik hubungan kadar aspal dan VMA

Berdasarkan grafik bisa diartikan, semakin tinggi kadar aspal yang dipakai, pori yang terisi aspal jadi banyak, sehingga angka VMA dapat ditingkatkan.

\section{e. VFB}

Dari tabel 8 bersama dengan kadar aspal 4,5\% $6,5 \%$ untuk Laston BASE didapat nilai VFB pada $66.15 \%-80.20 \%$. Pada aspal 4,5\%-6,5\% Nilai VFB
Volume 3 No.2, Juni 2021

e-ISSN 2775-4529

p-ISSN 2775-8613

Tabel 8. Pengujian VFB campuran Laston Base

\begin{tabular}{crrrrr}
$\begin{array}{c}\text { Kadar } \\
\text { Aspal }\end{array}$ & 4.50 & 5.00 & 5.50 & 6.00 & 6.50 \\
\hline & 14.67 & 15.55 & 16.31 & 17.18 & 18.07 \\
& & & & & \\
VMA & 14.65 & 15.53 & 16.29 & 17.25 & 18.05 \\
& 14.63 & 15.52 & 16.37 & 17.15 & 18.04 \\
$\begin{array}{c}\text { Rata- } \\
\text { rata }\end{array}$ & 14.65 & 15.53 & 16.32 & 17.20 & 18.05 \\
$\begin{array}{c}\text { syarat } \\
\text { syan }\end{array}$ & & & & & \\
\hline
\end{tabular}

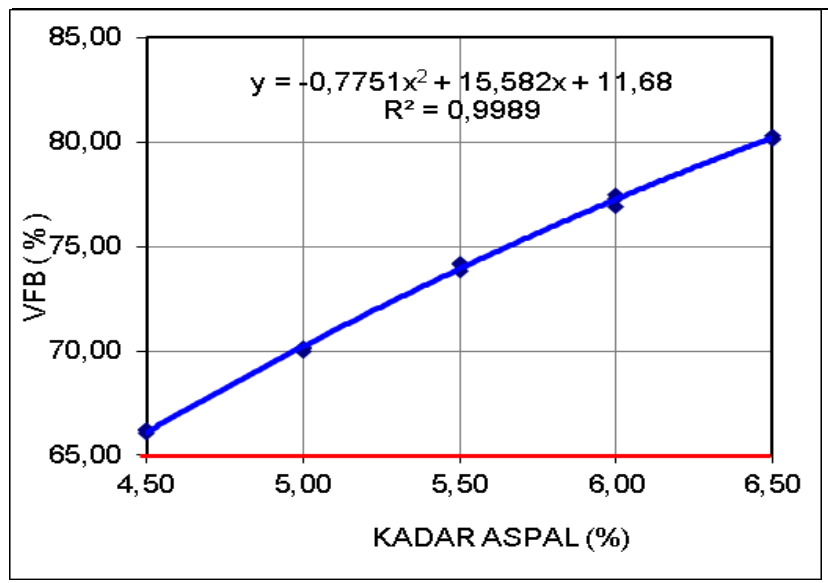

Gambar 7. Grafik hubungan kadar aspal dan VFB

Berdasarkan Gambar 7 dapat di ketahui pemakaian kadar aspal sedikit mengurangi VFB, dan pemakaian kadar aspal yang banyak maka tambah besar VFB, begitu pun sebaliknya.

\section{Penentuan Kadar Aspal Optimum}

Dari hasil pengujian campuran AC-BASE, ditentukan kadar aspal yang memenuhi kriteria campuran aspal. dan diambil dari Stabilitas tertinggi yaitu kadar aspal 5,5\% dimana fungsi laston AC$B A S E$ lalu yaitu melanjutkan beban selanjutnya kepada susunan Sub Grade.

\section{Stabilitas Marshall Sisa}


Paulus Civil Engineering Journal

Jurnal Teknik Sipil UKI-Paulus Makassar https://doi.org/10.52722/pcej.v3i2.3215

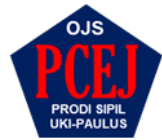

Volume 3 No.2, Juni 2021 e-ISSN 2775-4529 p-ISSN 2775-8613
Setelah pemilihan kadar aspal optimum, lalu memilih sampel sesuai kadar aspal optimum, yaitu aspal $5,5 \%$ AC-BASE lalu direndam sekitar \pm 24 jam dalam suhu $\pm 60^{\circ} \mathrm{C}$. adapun hasil pengujian Stabilitas Marshall Sisa, dapat diamati terhadap Tabel 9 berikut:

Tabel 9. Stabilitas Marshall Sisa untuk AC-BASE

\begin{tabular}{ccc}
\hline $\begin{array}{c}\text { SYARAT } \\
\begin{array}{c}\text { Kadar ASPAL } \\
(\%)\end{array}\end{array}$ & Min 90 & $\begin{array}{c}\text { Stabilitas Marsall } \\
\text { Sisa (\%) }\end{array}$ \\
\hline 5.50 & 2679,35 & 95,19 \\
5.50 & 2625,22 & 94,17 \\
5.50 & 2598,16 & 94,12 \\
Rata - Rata & & \\
Marshall & 2634,24 & 94,49 \\
Immersion & & \\
SYARAT & 94,50 & \\
\hline
\end{tabular}

Hasil uji Marshall Immersion didapatkan Stabilitas Marshall Sisa sebesar 96,06 \% yang mana sampel tahan akan temperatur, dan lama rendaman. Nilai kriteria rendaman sudah sesuai diisyaratkan Bina Marga terhadap Bab II yaitu $\geq 90 \%$. [8]

\section{KESIMPULAN}

Karakteristik agregat untuk campuran AC-BASE memenuhi Spesifikasi Bina Marga 2018. Begitu pula dengan karakteristik aspal dan karakteristik berat jenis filler yang telah memenuhi.

Adapun Komposisi AC-BASE yang melalui beberapa tahapan pengujian telah memenuhi syarat dan ketentuan yang berlaku

Berdasarkan hasil pengujian karakter campuran ACbase melalui uji marshall konvensional didapat karakter campuran aspal yang sesuai diisyaratkan seperti stabilitas. Kelelehan VIM VMA dan VFB. Nilai IKS dari hasil uji marshall immersion pada AC-base.

\section{DAFTAR PUSTAKA}

[1] R. Mangontan, 2020 "Pemanfaatan Batu Gunung Ambeso Pada Campuran AC-Base," Paulus Civil Engineering Journal, vol. 2.1, pp. 58-62

[2] A. Erdiansa, 2015,"Karakteristik Campuran ACBase dengan Aspal Penetrasi 60/70 dan
Penetrasi 80/100," prokons: Jurnal Teknik Sipil, vol. 9(1), p. $62-69$

[3] A. B. Angka and K. , 2017, "Slag Nikel Sebagai Bahan Subtitusi Pada Karakteristik Campuran AC-Base," seminar nasional hasil penelitian \& pengabdian kepada masyarakat (snp2m), vol. 1.1, pp. 89-94,

[3] M. T. Saifuddin, 2017, "Optimasi Penggunaan Aspal Penetrasi 60/70 pada Campuran Asphalt Concrete Base (ac-base)," kurva s jurnal mahasiswa, Vols. 1,1, pp. 1082-1100

[4] H. S. dan R. Marzuki, 2017, "Penggunaan Batu Pecah Palu dan Pasir Mahakam pada Campuran ac-base dengan Metode Marshall Test," kurva s jurnal mahasiswa, vol. 2.2, pp. 687-692

[5] D. N. Bunga, R. Rachman end M. Selintung, 2019, "Effect of Collision Variation towards the Index Retained Strength of Mixed Asphalt Concrete Wearing Course," International Journal of Scientific Engineering and Science, vol. 3, nr. 8, pp. 61-64.

[6] A. F. Mawardi, M. M. Khoiri and H. Gunawan, 2020, "Efek Variasi Suhu Pemadatan Campuran Laston Lapis Pondasi (AC-Base) dengan Penambahan Limbah Plastik," Jurnal Aplikasi Teknik Sipil, vol. 18(1), pp. 139-143

[7] R. Rachman, 2019, "Karakteristik Campuran HRS - BASE Menggunakan Bubuk Dolomit Sebagai Filler," in Prosiding Konferensi Nasional Teknik Sipil Ke-13 [KoNTekS-13], Banda Aceh.

[8] F. R. Saputra, 2016 "Komposisi Rancangan Aspal Beton AC-Base dengan Menggunakan Semen Sebagai Bahan Pengisi.," Kurva s jurnal mahasiswa, vol. 1(1), pp. 545-548

[9] R. Rachman, 2020, "Pemanfaatan Batu Gunung Bottomale Toraja Utara sebagai Campuran Laston," Jurnal Teknik Sipil dan Teknologi Konstruksi , vol. 6, nr. 1, pp. 20-30.

[10] Pramono, K. and Sopia Ayu Lestari, 2020, "Pengaruh Penggunaan Getah Karet Terhadap Stabilitas Marshall Pada Campuran Asphalt Concrete - Base (ac-base)," Journal inersia, vol. XII(1), pp. 44-50

[11] R. Rachman, 2020, "The Effect of Immersion and Humidification toward Performance of Hot 
Rolled Asphalt Mixture," International Journal of Applied Engineering Research, vol. 15, nr. 5, pp. 503 - 509, 2020.

[12] D. Pagewang, R. Rachman and A. 2020, "Pengaruh Penggunaan Limbah Kantong Plastik Sebagai Bahan Tambah dalam Campuran Ac - Base," Paulus Civil Engineering Journal, vol. 2(2), pp. 97-102
[13] D. J. B. Marga, 2018, Spesifikasi Umum Bina Marga, Jakarta Indonesia: Kementerian Pekerjaan Umum dan Perumahan Rakyat

[14] Sumardi, R. Rachman end J. Tanijaya, 2019, "Study of the Use Bagasse Ash as a Filler Replacement to Characteristics Asphalt Concrete," International Journal of Scientific Engineering and Science, vol. 3, nr. 8, pp. 6570. 